\title{
Genome-wide identification and expression analysis of the EX070 gene family in grape (Vitis vinifera L)
}

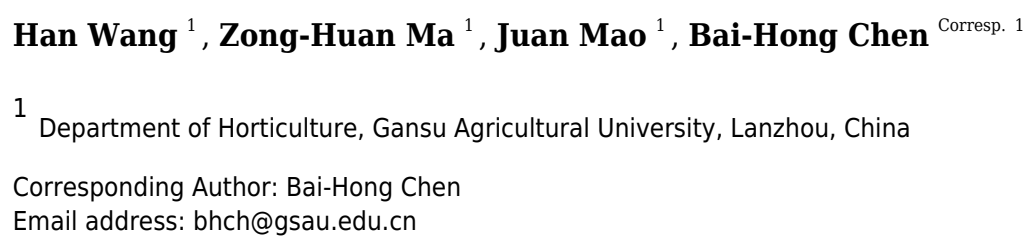

EXO70 is the pivotal protein subunit of exocyst, which has a very crucial role in enhancing the shielding effect of cell wall, resisting abiotic and hormonal stresses. This experiment aims to identify family members of the EXO70 gene family in grape and predict the characteristics of this gene family, so as to lay the foundation of further exploring the mechanism of resisting abiotic and hormone stresses of VVEXO70s. Therefore, the Vitis vinifera 'Red Globe' tube plantlet were used as materials. Bioinformatics was used to inquire VvEXO70 genes family members, gene structure, system evolution, cis-acting elements, subcellular and chromosomal localization, collinearity, selective pressure, codon bias and tissue expression. All of VvEXO70s had the conserved pfam03081 domain which maybe necessary for interacting with other proteins. Microarray analysis suggested that most genes expressed to varying degrees in tendrils, leaves, seeds, buds, roots and stems. Quantitative Real-Time PCR(qRT-PCR ) showed that the expression levels of all genes with $5 \mathrm{mM}$ salicylic acid (SA), $0.1 \mathrm{mM}$ methy jasmonate (MeJA), 20\% PEG6000 and $4{ }^{\circ} \mathrm{C}$ for $24 \mathrm{~h}$ were higher than for $12 \mathrm{~h}$. With 20\% PEG6000 treatment about $24 \mathrm{~h}$, the relative expression of VVEX070-02 was significantly up-regulated and 361 times higher than CK. All genes' relative expression was higher at $12 \mathrm{~h}$ than that at $24 \mathrm{~h}$ after treatment with $7 \mathrm{mM}$ hydrogen peroxide $\left(\mathrm{H}_{2} \mathrm{O}_{2}\right)$ and $0.1 \mathrm{mM}$ ethylene $(\mathrm{ETH})$. In conclusion, the expression levels of 14 VVEXO70 genes are distinguishing under these treatments, which play an important role in the regulation of anti-stress signals in grape. All of these test results provide a reference for the future research on the potential function analysis and plant breeding of VvEXO70 genes. 
1 Genome-wide identification and expression analysis of the EXO70 gene family in grape

2 (Vitis vinifera $\mathrm{L}$ )

3

4 Han Wang, Zonghuan Ma, Juan Mao, Baihong Chen*

5 College of Horticulture, Gansu Agricultural University, Lanzhou 730070, PR China

6

$7 \quad *$ Corresponding author. E-mail address: bhch@gsau.edu.cn

8

9 Abstract

EXO70 is the pivotal protein subunit of exocyst, which has a very crucial role in enhancing the shielding effect of cell wall, resisting abiotic and hormonal stresses. This experiment aims to identify family members of the EXO70 gene family in grape and predict the characteristics of this gene family, so as to lay the foundation of further exploring the mechanism of resisting abiotic and hormone stresses of $V v E X O 70 s$. Therefore, the Vitis vinifera 'Red Globe' tube plantlet were used as materials. Bioinformatics was used to inquire VvEXO70 genes family members, gene structure, system evolution, cis-acting elements, subcellular and chromosomal localization, collinearity, selective pressure, codon bias and tissue expression. All of VvEXO70s had the conserved pfam03081 domain which maybe necessary for interacting with other proteins. Microarray analysis suggested that most genes expressed to varying degrees in tendrils, leaves, seeds, buds, roots and stems. Quantitative Real-Time PCR(qRT-PCR) showed that the expression levels of all genes with $5 \mathrm{mM}$ salicylic acid (SA), $0.1 \mathrm{mM}$ methy jasmonate (MeJA), $20 \%$ PEG6000 and $4{ }^{\circ} \mathrm{C}$ for $24 \mathrm{~h}$ were higher than for $12 \mathrm{~h}$. With 20\% PEG6000 treatment about $24 \mathrm{~h}$, the relative expression of $V v E X O 70-02$ was significantly up-regulated and 361 times higher than CK. All genes' relative expression was higher at $12 \mathrm{~h}$ than that at $24 \mathrm{~h}$ after treatment with 7 $\mathrm{mM}$ hydrogen peroxide $\left(\mathrm{H}_{2} \mathrm{O}_{2}\right)$ and $0.1 \mathrm{mM}$ ethylene $(\mathrm{ETH})$. In conclusion, the expression levels

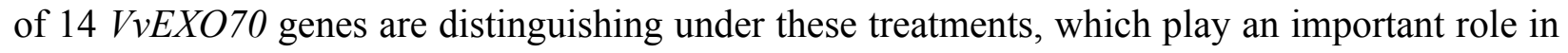
the regulation of anti-stress signals in grape. All of these test results provide a reference for the 
future research on the potential function analysis and plant breeding of $V v E X O 70$ genes.

\section{INTRODUCTION}

The yield and quality of plants under biotic and abiotic stresses are seriously damaged, so it is essential to explore the defense mechanism (BU et al., 2019). When plants are under biotic and abiotic stresses, the signaling pathway related to receptor proteins is activated and exocytosis occurs, which enhances the shielding effect of cell wall (Yun et al., 2017). Exocytosis refers to the process of the transport vesicles derived from the post-golgi transport membrane fuse with the target membrane pass through certain transport pathways (Jurgens et al., 2002). It plays a very important role in all eukaryotic cells, including cell growth, cell polarization, cell division, cell information transfer, the formation of the cell walls of the physiological process (Yao et al., 2013; Yang et al., 2013; Yang et al., 2015), especially has a crucial role in plant resistance mechanisms (Gu et al., 2017).

EXO70 is one of the 8 protein subunits in the exocrine complex, with the other 7 ones (SEC3、SEC5、SEC6、SEC8、SEC10、SEC15 and EXO84), is involved in the tethering process of the membrane vesicles at the budding site. The tethering process is the third step (budding, transport, tethering, fusion) in the material exchange process of different membrane structures in the cell, which is involved in the initial contact process of the transport vesicles and the target membrane and is a key step in regulating extracellular secretion (TerBush et al., 1995; TerBush et al., 1996; Finger et al., 1998; Guo et al., 1999; Whyte et al., 2002; Cai et al., 2007). The C-terminal of EXO70 protein carries several negative charge residues (Zhu et al., 2019), and EXO70 and SEC3 can bind to phosphatidylinositol-4, 5-diphosphate (PIP2), which is involved in the anchoring of exocrine complex secretory tomont and target plasma membrane (Liu et al., 2018). Meanwhile, EXO70 can directly interact with Rho GTPase family members of small G protein, participating in the assembly and activation of SNARE protein and regulating the assembly of exocyst complex (Sivaram et al., 2005; He et al., 2007; Moore et al., 2007; Wu et al., 2010; Chen et al., 2012; Ren et al., 2012).

The mechanism of exocyst was first identified in yeast studies. EXO70 was localized at the 
56

57

58

59

60

61

62

63

activation site of vesicle-plasma membrane fusion in yeast (Mathieson et al., 2010). In animals, 8 proteins of yeast-homologous exocrine complex were first isolated in the brain tissues of mice (Ma et al., 2016). EXO70 gene families of yeast and animals have only one member, meanwhile, there are multiple members in EXO70 gene family of plants, which shows the multi-copy phenomenon peculiar to plants (Table S1) (Moore et al., 2007; Yang et al., 2013). For example, the genes encoding SEC6, SEC8 and SEC10 in the Arabidopsis thaliana genome have only one copy respectively, while the genes encoding EXO70 have 23 copies. The genes encoding SEC5, SEC6, SEC8 and SEC10 in the rice genome had only one copy each, while the genes encoding EXO70 had 47. This indicates that the replication of EXO70 gene is unique to terrestrial higher plants ( $\mathrm{Li}$ et al., 2010). The cause of this phenomenon has not been determined, and it is speculated that the EXO70 genes in different organisms are involved in various biological processes (Bu et al., 2019). Studies have found that exocytosis of higher plants acts on plant growth and development (Jurgens et al., 2002). Among the 23 A. thaliana EXO70 genes, AtEXO70A1 was involved in the growth of pollen tube and root hairs, resulting in shorter root and stigma hairs (Synek et al., 2006; Samuel et al., 2009). AtEXO70C1(At5g13150) gene mutated, resulting in delaying pollen tube development and blocking male transmission ( $\mathrm{Li}$ et al., 2010). Moreover, EXO70 is involved in pollen-stigma interactions in Brassica and the overexpression of $B r E X O 70 A 1$ is sufficient to overcome the self-pollination rejection of the species with partial self-incompatibility (Samuel et al., 2009; Zhang et al., 2010). During the development and maturation of Glycine $\max \mathrm{L}$, the expression of some GmExo70J genes including GmExo70J1, GmExo70J6 and GmExo70J7 increases greatly in floral organ-supporting receptacles, indicating a possible role in seed development (Wang et al., 2016).

At present, the EXO70 gene in yeast and mammals has been widely studied, but only a few kinds of plants have been done, such as tomato (Solanum lycopersicum) had 22, potato (Solanum tuberosum) had 21, tobacco (Nicotiana benthamiana) had 44 (Yu et al., 2018), A. thaliana had 23 (Li et al., 2010), Chinese cabbage (Brassica pekinensis) had 39, cabbage (Brassica oleracea) had 45 (Yang et al., 2015 ), diploid tobacco had 24 (Juraj et al., 2017), wheat (Triticum aestivum) 
83

84

had 200 (Zhao et al., 2018) EXO70 genes. However, the study of EXO70 gene families in grape rarely reported. Besides, genome-wide identification and expression analysis are effective ways to clarify the classification and composition of gene family members in genome, which is the primary task to explore biological issues related to species characteristics. These can lay a foundation for subsequent functional studies and genetic manipulation of gene. Therefore, in this study, a genome-wide identification and expression analysis of $V v E X O 70$ gene family was conducted and bioinformatics was used to inquire $V v E X O 70$ gene family members, genetic structure, system evolution and cis-acting element, subcellular and chromosomal localization, collinearity, selective pressure, codon bias and tissue expression. By establishing the simulation environment of different treatment for grape test-tube seedlings and analyzing the relative expression quantity, it could provide the reference for the further research of the function of the gene family and the breeding of resistant varieties in grape.

\section{MATERIALS AND METHODS INTRODUCTION}

\subsection{Overview of study}

As shown below, the experiment mainly included genome-wide identification and expression analysis of EXO70 gene family in grape to preliminarily predict the function of $V v E X O 70 \mathrm{~s}$. On the one hand, we identified the members of $V v E X O 70 s$ by bioinformatics and on the other hand, we analyzed the responses of this gene family to some abiotic stresses by qRT-PCR. These test results could provide a reference for the future research on the potential function analysis and plant breeding of $V v E X O 70$ genes. 
Identification and expression analysis

of the EXO70 gene family in grape

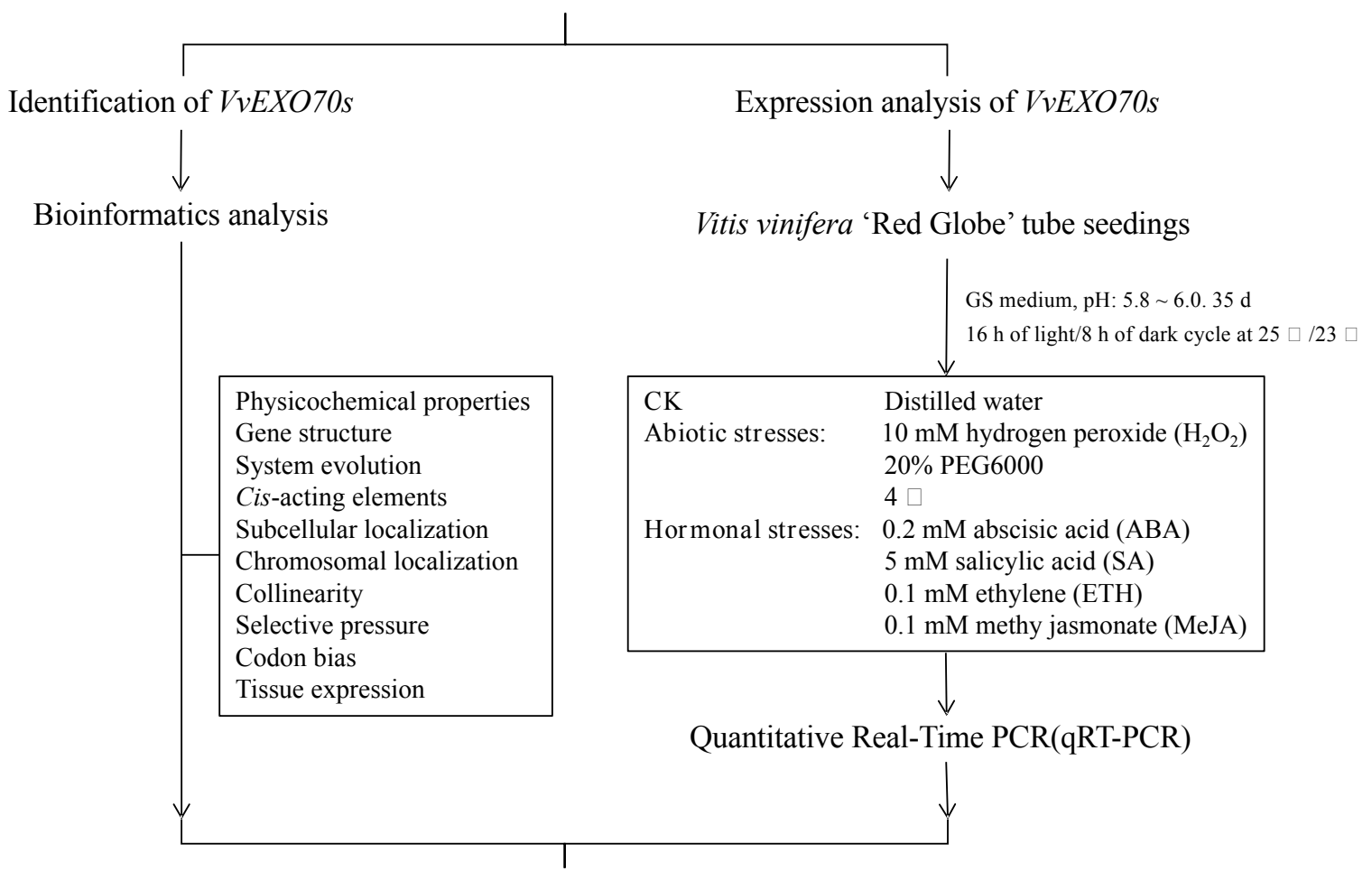

$14 V v E X O 70$ genes were likely to play critical roles in the abiotic and hormonal stresses signaling transduction pathways

106

107

108

109

110

\subsection{Plant materials and treatments}

The experiment materials were Vitis vinifera 'Red Globe' tube seedings, which were stored in College of Horticulture, Gansu Agricultural University. At the beginning of the test, we placed stem-segment with single bud of tube seedlings on ordinary GS medium and pH was $5.8 \sim 6.0$.

Materials were cultured in the incubator under a $16 \mathrm{~h}$ of light $/ 8 \mathrm{~h}$ of dark cycle at $25^{\circ} \mathrm{C} / 23^{\circ} \mathrm{C}$. Different stress treatments were conducted about $35 \mathrm{~d}$ seedling plants. For abiotic stress treatments, the seedlings were incubated in a solution containing 20\% PEG6000, $10 \mathrm{mM}$ hydrogen peroxide $\left(\mathrm{H}_{2} \mathrm{O}_{2}\right)$ and the low temperature treatment condition is $4{ }^{\circ} \mathrm{C}$. For phytohormone treatment, the seedlings were cultured in GS medium with $5 \mathrm{mM}$ salicylic acid (SA), $0.1 \mathrm{mM}$ methy jasmonate (MeJA), $0.1 \mathrm{mM}$ ethylene (ETH) and $0.2 \mathrm{mM}$ abscisic acid (ABA) respectively, meanwhile, the volume of distilled water as a CK. Every stress repeated 
118 three times. Then we collected leaves from each treatment about $12 \mathrm{~h}$ and $24 \mathrm{~h}$. All of the

119 collected materials were stored at $-80{ }^{\circ} \mathrm{C}$ for RNA extraction and gene expression analysis.

120

121

122

123

124

125

126

127

128

129

130

131

132

133

134

135

136

137

138

139

140

141

142

143

144

145

\subsection{Identification of EXO70 genes family members in grape and analysis of physicochemical properties}

A. thaliana IDs (Li et al.,2010; Zhao et al.,2018) were used to download amino acid sequences of each gene from TAIR database (https://www.arabidopsis.org). After that amino acid sequences were used to homologously search EXO70 genes family in grape genome website (http://www.genoscope.cns.fr/) and rice genome website (http://rice.plantbiology.msu.edu/). We could screen genes by judging whether they include the functional domain 'PF03081.15' on HMMER (https://www.ebi.ac.uk/Tools/hmmer/). Meanwhile, DNAMAN software could do multiple sequence alignment. ExPASy (https://web.expasy.org/protparam/) was used to acquire some basic physicochemical properties about $V v E X O 70$ s such as the number of exon, molecular weight (MW), isoelectric point (pI), instability index (I.I), aliphatic index (A.I), grand average of hydropathicity (GRAVY).

\subsection{Bioinformatics analysis of the VvEXO70s}

Clustal X, MEGA7.0 and EvolView (https://www.evolgenius.info//evolview/\#login) were used to constructed phylogenetic trees of grape, rice and $A$. thaliana EXO70 genes by the basis of the neighbor-joining method. The bootstrap analysis was performed using 1,000 repetitions. The gene structure of the $V v E X O 70 s$ was detected by using GSDS 2.0 (http://gsds.cbi.pku.edu.cn/) based on their corresponding amino acid sequences. The secondary structure was identified on NPS@:SOPMA (https://npsa-prabi.ibcp.fr/cgi-bin/npsa_automat.pl?page=npsa_sopma.html). The 3D structure was created with SWISS-MODEL (https://swissmodel.expasy.org/). The chromosomal location information of $V v E X O 70 s$ was obtained from the grape genome website (http://www.genoscope.cns.fr/) and was drawn a picture by MG2C (http://mg2c.iask.in/mg2c_v2.0/). MEME (http://meme-suite.org/tools/meme) was used to analyze the conserved motifs of VvEXO70 proteins. Subcellular localization analysis was 
conducted on WoLF PSORT (https://www.genscript.com/wolf-psort.html). PLACE (http://www.dna.affrc.go.jp/PLACE/signalscan) was used to analyze the distribution of cis-acting elements of the $2 \mathrm{~kb}$ of upstream of $14 V v E X O 70$ genes.

\subsection{Collinearity and selective pressure analysis VvEXO70s}

Online software (http://tools.bat.infspire.org/circoletto/) was used to analyze the collinearity of EXO70 genes between grape and A. thaliana.

Pairs of genes with collinearity would be done sequence alignment by using Clustal Omega (https://www.ebi.ac.uk/Tools/msa/clustalo/).

PAL2NAL (http://www.bork.embl.de/pal2nal/index.cgi?) was used to calculate the nonsynonymous/synonymous $\left(\mathrm{d}_{\mathrm{N}} / \mathrm{d}_{\mathrm{S}}\right)$ value of duplicate gene pairs (Goldman et al., 1994).

\subsection{Codon usage bias analysis VvEXO70s}

Codon composition and usage preference of $V v E X O 70$ gene family members were analyzed by CodonW software. Relative synonymous codon usage (RSCU) refers to the ratio of the frequency used by a particular codon to the frequency expected in unbiased use. Measures of codon use preference include : RSCU, number of valid codons (ENC), codon adaptation index (CAI), and codon bias index (CBI). Measures indicators of codon composition include : the occurrence frequency of adenine, thymine, guanine, and cytosine at position 3 (A3s, T3s, G3s, $\mathrm{C} 3 \mathrm{~s}$ ), frequency of optimal codons (FOP), Guanine and cytosine content (GC content), GC content at the third site of the synonymous codon (GC3s content), aromatic amino acid frequency (Aromo), synonymous codon number ( $\mathrm{L}_{-}$sym), the total number of synonymous and non-synonymous codons (L_aa), protein hydrophilicity (Gravy). Correlation analysis between codon composition and preference parameters was carried out by using SPSS 23.0 statistical software.

\subsection{Tissue-specific expression patterns of VvEXO70s}

BLAST program on Ensembl Plants (http://plants.ensembl.org/index.html) was used to find the accession numbers of tissue-specific expression of $V v E X O 70 \mathrm{~s}$. These ids were used to gain the 
175

176

177

178

179

180

181

182

183

184

185

186

187

188

189

190

191

192

193

194

195

196

197

198

199

200

201

tissue-specific expression data related to the different tissues at various developmental stages of grape on BAR (https://bar.utoronto.ca/). R language was used to visualize the results.

\subsection{RNA Isolation and qRT-PCR analysis of VvEXO70s}

The RNA were extracted from plant leaves by using a Spectrum Plant Total RNA kit (Sigma St. Louis, MO, USA) following the operating instructions.

The primer design and synthetic were accomplished in Sangon Biotech in Shanghai. The Reverse Transcriptase M-MLV (RNase H-) kit (TaKaRa Biotechnology. Lanzhou, China) was used to synthesize cDNA. Light Cycler® 96 Real-Time PCR System (Roche, Basel, Switzerland) was used to perform qRT-PCR of VvEXO70s. The gene primers (Table S2) were designed in Sangon and used for PCR amplification, among which GAPDH gene (GenBank accession no. CB973647) was internal control genes. The amplification volume was $25 \mu \mathrm{L}$ containing $1 \mu \mathrm{L}$ forward primer, $1 \mu \mathrm{L}$ reverse primer, $1.5 \mu \mathrm{L}$ cDNA, $9 \mu \mathrm{L} \mathrm{ddH}_{2} \mathrm{O}$ and $12.5 \mu \mathrm{L}$ TaKaRa SYBR Premix Ex Taq. II (TaKaRa Biotechnology. Lanzhou, China). The response procedures was: $95{ }^{\circ} \mathrm{C}$ for $30 \mathrm{~s}, 40$ cycles of $95{ }^{\circ} \mathrm{C}$ for $5 \mathrm{~s}$, and $60{ }^{\circ} \mathrm{C}$ for $30 \mathrm{~s}$. For melting curve analysis, a program including $95{ }^{\circ} \mathrm{C}$ for $15 \mathrm{~s}$, followed by a constant increase from $60{ }^{\circ} \mathrm{C}$ to $95{ }^{\circ} \mathrm{C}$, was included following the PCR

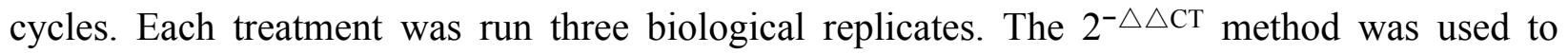
calculate the relative expression levels of genes (Udvardi et al., 2008).

\section{RESULTS}

\subsection{Identification and physicochemical characterization of VvEXO70s}

$14 V v E X O 70$ genes were homologously searched and named as $V v E X O 70-01 \sim V v E X O 70-14$. Chromosome localization (Fig. 1) showed that the location of $V v E X O 70-02$ was unknown and the other 13 genes located on 8 chromosomes of grape, named Chr01 ${ }^{\text {st }}$, Chr04 ${ }^{\text {nd }}, \mathrm{Chr} 6^{\text {th }}, \mathrm{Chr} 8^{\text {th }}$, Chr09' ${ }^{\text {th }} \mathrm{Chr}^{\text {th }}, \mathrm{Chr} 14^{\text {th }}$ and Chr17 ${ }^{\text {th }}$. Both $V v E X O 70-09$ and $V v E X O 70-10$ were located on the same site of $\mathrm{Chr09}^{\text {th }}$ and belonged a pair of tandem duplication genes. The physicochemical properties of $V v E X O 70 s$ suggested that the number of amino acids mainly were concentrated in 
$202610 \sim 690$ aa, among them $V v E X O 70-13$ had 452 aa. In all genes, the number of MW of $203 V v E X O 70-06(77426.01 \mathrm{kD})$ was the largest and the minimum is $V v E X O 70-07(51585.27) \mathrm{kD}$. 204 Also, the number of exons was mainly 1, 2, and 3, but the exons of $V v E X O 70-02$ and $V v E X O 70$ 20505 were 12 and 11 , respectively (Table 1).

206

\subsection{Analysis of gene structure, and subcellular localization of VvEXO70s}

Secondary structural analysis (Table S3) showed that the $V v E X O 70$ gene family was mainly composed of alpha-helix and random coil, and the proportion of the two was similar, with the proportion of beta-turn, not more than $10 \%$. The tertiary structure showed that $V v E X O 70-09$, $V v E X O 70-10$ and $V v E X O 70-12$ were similar and greatly different from the rest of the genes (Fig S1).

Subcellular localization (Table S4) found that most of the EXO70 proteins may be locate in the nucleus, cytoplasm, chloroplasts, mitochondria, and plasma membrane. Except for VvEXO70-08 and VvEXO70-11, other proteins would locate in the cytoplasm and nucleus, among which VvEXO70-05 was possibly the most abundant in the cytoplasm, and VvEXO70-01 and VvEXO70-07 were potentially the richest in the nucleus. VvEXO70-08 scored the highest probability to be present only in the chloroplast, In the mitochondria, VvEXO70s maybe have low content. VvEXO70-01 and VvEXO70-03 only potentially existed in peroxidases. VvEXO70-03 and VvEXO70-04 only possibly located in cytoskeleton. There were six genes would locate in the plasma membrane, among which VvEXO70-11 was possibly the most abundant. VvEXO70-06 and VvEXO70-13 could locate in the extracellular matrix. There was only one gene possibly located in the nuclear and nuclear and plasma membrane respectively, and these were VvEXO70-04 and VvEXO70-05. We predicted that genes locating in different organelles have different physiological functions, such as photosynthesis, growth and development and the like.

\subsection{Phylogenetic evolution, Multiple sequence alignment and motif analysis of VvEXO70s}

In this study, all 77 EXO70 protein sequences of grape (14), A. thaliana (23) and rice (40) were 
230

231

232

233

234

235

236

237

238

239

240

241

242

243

244

245

246

247

248

249

250

251

252

253

254

255

256

257

used to construct phylogenetic tree. Fig. 2 showed that they were divided into 10 sub-groups, namely EXO70A $\sim \mathrm{J}$, which consisted $11,6,5,7,9,11,16,2,8$ and 2 members respectively. Sub-group EXO70A, B, C, D, E, and G contained grape, A. thaliana and rice genes. EXO70F, H and $\mathrm{J}$ did not contain the $V v E X O 70$ genes but only rice genes. Meanwhile, Fig. 3 A showed that the groups of the separate cluster analysis of $V v E X O 70$ only had seven ones.

Besides, Fig. 3 B showed that all $V v E X O 70$ genes had different structures. $V v E X O 70-03$, $V v E X O 70-04, V v E X O 70-08$, and $V v E X O 70-13$ had only CDS fragments, no upstream and downstream gene sequences and introns. $V v E X O 70-09$ and $V v E X O 70-14$ had the upstream gene sequence. $V v E X O 70-02$ and $V v E X O 70-05$ had the downstream gene sequence. Among all the genes, $V v E X O 70-07$ was the only one gene containing upstream and downstream sequences in all genes. $V v E X O 70-02$ had the longest fragment length that was more than $33 \mathrm{~kb}$. Moreover, cluster analysis of genes with similar structure was found in the same subgroup.

In this experiment, 8 motifs were constructed and named motifl $\sim 8$. The result (Fig. 3 C) showed that $V v E X O 70-07$ did not have motif8, $V v E X O 70-12$ had no motif3. This was consistent with the result of multiple sequence alignment (Fig. 3 D), which showed that $V v E X O 70-12$ had no complete motif3 and the motif8 of $V v E X O 70-07$ was incomplete. The remaining genes contained all motifs. It indicated that the gene family structure was similar and had certain conservatism in evolution.

Protein sequences of the VvEXO70 family were compared and some regions were intercepted (Fig. 3 D). It mainly contained the specific structure domain 'PF03081.15' with base loci from about $250 \sim 650$ aa. Within its domain, it contained 15 highly conserved loci representing by red boxes in the Fig. 3 D. At the same time, two highly fractured zones were found in the conservative structure domain, which were named by A and B in it, we speculated that the gene family had some variation during the evolutionary process.

\section{4. cis-acting element analysis of VvEXO70s}

The analysis of cis-acting elements is very important to understand the regulatory mechanism of genes. The online plant-care software tool was used to analyze the codon in the promoter 
258

259

260

261

262

263

264

265

266

267

268

269

270

271

272

273

274

275

276

277

278

279

280

281

282

283

284

285

sequences of $2 \mathrm{~kb}$ upstream of $V v E X O 70$ gene, and it was found that the regulatory elements of the $V v E X O 70$ s were very abundant in number and variety. Main 24 types of hormone and stress related cis-acting regulatory elements were identified in the promoters of $V v E X O 70$ genes (Fig. 4). However, we found nothing about the functional components of $V v E X O 70-02$ on the online site. Emphasis was placed on the analysis of cis-acting elements in $V v E X O 70$ genes related to grape growth and development, hormones and abiotic stress response. There are mainly the following types.

cis-acting element involved in light responsiveness ; Box-4、G-box. cis-acting element involved in hormone: CGTCA-motif and TGACG-motif are related to MeJA responsive element. GAREmotif and P-box are related to Gibberellin-responsiveness responsive element. TCA-element and as-1 are related to SA responsive element, as well as Auxin responsive element and Abscisic acid responsive element. In addition, there are cis-acting regulatory element involved in circadian control, cell cycle regulation and abiotic stress, including low temperature responsive element, WUN-motif element and anaerobic induction element, MYB binding site involved in droughinduibility and so on. Fig. 4 and Table S5 showed that all of $V v E X O 70 s$ except $V v E X O 70-02$ contained different species numbers of cis-acting elements. $13 V v E X O 70$ genes contained G-box and Box-4 elements associated with light stress and MYB and MYC elements associated with drought. In addition, there are 28, 30 and 40 elements related to SA, MeJA and ET. The results suggested that the $V v E X O 70$ s were involved in regulating various hormones and abiotic stresses to cope with various adverse environments.

\subsection{Analysis of collinearity and selective pressure between grape and $A$. thaliana EXO70 genes}

The online software was used to obtain the collinearity relationship of EXO70 genes between grape and $A$. thaliana (Fig. 5). It was found that there were 23 pairs of collinearity genes between grape and $A$. thaliana. Red indicated the lowest similarity, followed by orange, green and blue, indicating the decreasing similarity. For example, in the red ribbon, $V v E X O 70-02$ and AtEXO70A1, VvEXO70-05 and AtEXO70A2, VvEXO70-12 and AtEXO70G1, VvEXO70-13 and 
286

287

288

289

290

291

292

293

294

295

296

297

298

299

300

301

302

303

304

305

306

307

308

309

310

311

312

313

AtEXO70D2 had the strongest collinearity. There were 6 pairs of genes with collinear relationship on orange degree. The next weaker collinearity was found in 11 pairs of genes. However, the two weakest pairs were $V v E X O 70-08$ and AtEXO70H6, $V v E X O 70-08$ and AtEXO70H8. In addition, the collinear relationship between $V v E X O 70$ and AtEXO70 was one to many, such as the collinear relationships between $V v E X O 70-08$ and AtEXO70H5, AtEXO70H6, AtEXO7OH7 and AtEXO7OH8 were be in varying degrees.

In the process of gene evolution, mutations include synonymous mutation and non-synonymous mutation, and 3 important values, named the synonymous mutation frequency $\left(\mathrm{d}_{\mathrm{S}}\right)$ and the nonsynonymous mutation frequency $\left(\mathrm{d}_{\mathrm{N}}\right)$ and the ratio of $\mathrm{d}_{\mathrm{N}} / \mathrm{d}_{\mathrm{S}}$. The value of $\mathrm{d}_{\mathrm{N}} / \mathrm{d}_{\mathrm{S}}$ plays an important role in gene selection and evolution. When $d_{N} / d_{S}>1$ is the positive selection, $d_{N} / d_{S}=1$ is the neutral selection, $0<\mathrm{d}_{\mathrm{N}} / \mathrm{d}_{\mathrm{S}}<1$ is purifying selection (Yang et al., 2000; Yadav et al., 2015). To further explore the evolutionary pattern of this gene family, we found that the values of $d_{N} / d_{S}$ of all 23 duplicated gene pairs were less than 1 between grape and A. thaliana, indicating that the evolution pattern was purifying selection, which played a crucial role in keeping the number of EXO70 in grape and could help to maintain the basic function of this gene (Table 2).

\subsection{Analysis of base number and codon usage bias of VvEXO70s}

RSCU is the ratio of the actual value used by the codon to the theoretical value used by that(Sharp et al., 1986; Sharp et al., 1987). The theoretical value is the value with the same frequency of codon, that is, there is no codon bias. If $\operatorname{RSCU}=1$, the use of codon has no preference. If $\mathrm{RSCU}>1$, it indicates that the codon is used more frequently than other synonymous codons, named a high-frequency codon. If $\operatorname{RSCU}<1$, the codon is used less frequently than other codons (Lin et al., 2002; Li et al., 2016). RSCU values results (Table S6) of $V v E X O 70 s$ codon showed that $14 V v E X O 70$ genes contained a total of 8871 codons (excluding the termination codon). Among them, there were 5984 codons' RSCU>1, 2620 codons ending in $\mathrm{A} / \mathrm{U}$, and 3364 codons ending in $\mathrm{C} / \mathrm{G}$, accounting for $43.78 \%$ and $52.22 \%$ of the total codons of RSCU $>1$, respectively. This suggested that the codon ending in $\mathrm{C} / \mathrm{G}$ was the preferred codon of the EXO70 gene family. Among all codons, the RSCU value of AGG codon of $V v E X O 70-10$ 
314 gene was the highest (3.18). Some RSCU values of codons ending in G/C differed from others, 315 for example, RSCU values of UUC codons of $V v E X O 70-01, V v E X O 70-04, V v E X O 70-06$, $316 V v E X O 70-07$ and $V v E X O 70-08$ were greater than 1, while RSCU values of other UUC codons 317 were less than 1.

318 Analysis of the codons usage parameters of $V v E X O 70 s$ is shown in Table S7. ENC, CAI and CBI 319 values were used to predict gene expression levels. The ENC value of the effective codon ranges 320 from 20 to 61 , and the smaller the value, the stronger the applicability of the gene codon (Gupta 321 et al., 2004; Satapathy et al., 2017). When the use bias reaches the maximum degree, the ENC 322 value is 20; The smaller the usage bias, the closer to 61 (Wright et al., 1990). The higher the 323 codon preference was, the higher the gene expression level was, and the ENC value was negatively correlated with CAI and CBI values. Low expression gene has low preference, and its CAI and CBI values are small, which will be affected by the amino acid composition and gene length of the gene (Wright et al., 1990; Marashi et al., 2004). Furthermore, we found the average of ENC of $V v E X O 70 s$ was 54.84, the minimum value was 53.2 ( $V v E X O 70-10)$, and the maximum value was 59.07 ( $V v E X O 70-07)$, indicating that the codon preference of this gene family was weak and the usage degree of deviation from random selection was relatively consistent. In general, CAI and CBI values were positively correlated, with values ranging from 0 to 1 . Genes, with higher expression, had higher CAI and CBI values. The closer to 1 , the higher the value, and the stronger the codon preference (Wu et al., 2007). In addition, the CAI mean of $V v E X O 70 \mathrm{~s}$ was 0.203 and the CBI mean was -0.031 . The above results indicated that VvEXO70 gene family had weak codon preference. Among them, CAI and CBI values of $V v E X 070-01$ were the maximum values, which were 0.267 and 0.102 respectively. In addition, the Fop value of $V v E X O 70-01$ gene was the maximum value among all members, indicating that the gene contained the codon with the highest frequency of usage. Further analysis of GC contents of $14 V v E X O 70$ genes and $\mathrm{GC}, \mathrm{A}, \mathrm{T}, \mathrm{C}$ and $\mathrm{G}$ in the third place of the codon showed that the average G3s content was $36.97 \%$ and the average C3s content was $29.29 \%$. The average 340 content of $\mathrm{T} 3 \mathrm{~s}$ and $\mathrm{A} 3 \mathrm{~s}$ was $34.94 \%$ and $26.71 \%$, respectively. The average GC content was 
$34146.80 \%$, and the average GC3s content was $50.60 \%$. This indicated that the base selection of the

342 third position of the code of $V v E X O 70$ s had a weak $\mathrm{C} / \mathrm{G}$ preference, and the codon ending in $\mathrm{C} / \mathrm{G}$ 343 was preferred.

344 Correlation coefficient between parameters of $V v E X O 70 s$ codon usability (Table S8) showed that

345 CAI values, CBI values and FOP values were extremely positively correlated with each other $346(\mathrm{p}<0.01)$. C3s values were extremely positively correlated with CBI, Fop, GC3s and GC values $347(\mathrm{p}<0.01)$. GC3s values were extremely positively correlated with $\mathrm{GC}$ values $(\mathrm{p}<0.01)$. L_sym 348 and L_aa values were extremely positively correlated $(\mathrm{p}<0.01)$. GC values were positively 349 correlated with CBI and Fop values $(\mathrm{p}<0.05)$. T3s values were extremely negatively correlated 350 with $\mathrm{C} 3 \mathrm{~s}, \mathrm{CBI}$, Fop, GC3s and $\mathrm{GC}$ values $(\mathrm{p}<0.01)$. A3s values were extremely negatively 351 correlated with $\mathrm{C} 3 \mathrm{~s}$ and $\mathrm{GC} 3 \mathrm{~s}$ values $(\mathrm{p}<0.01)$, and negatively correlated with GC values $352(\mathrm{p}<0.05)$. ENC values were negatively correlated with L_sym and L_aa values $(\mathrm{p}<0.05)$. It 353 showed that the base content in the third position of the synonymous codon had a high influence 354 on the gene expression level and codon preference (Zhang et al., 2011).

355

356

357

358

359

360

361

362

363

364

365

366

367

368

\subsection{Microarray of VvEXO70s}

Expression patterns of all $V v E X O 70$ from transcriptomic data from grape organs and tissues at different stages of development and under abiotic stress were studied (Fig. 6). The data were mainly from a total of 54 grapevine samples, covering most of the grape organs at different stages, were collected. Three biological replicates were taken for each sample, resulting in a total of 162 observations. The collected plant organs were: bud, inflorescence, tendril, leaf, stem, root, developing berry, withering berry, seed, rachis, anther, carpel, petal, pollen, and seedling. The results showed that most genes are expressed to varying degrees in tendrils, leaves, seeds, buds, roots and stems. Among them, $V v E X O 70-01$ was mainly found in pollen and stamens, with the highest expression in pollen. $V v E X O 70-02$ was mainly found in pericarp-veraison, seed-veraison and skin-veraison. $V v E X O 70-04$ was detected in bud-winter dormant, pericarp-veraison, seedveraison and flesh-PHWI, and its expression level was relatively higher than that of other genes. In all the tissues, $V v E X O 70-05$ had the highest content in stamens, followed by pollen and 
369

370

371

372

373

374

375

376

377

378

379

380

381

382

383

384

385

386

387

388

389

390

391

392

393

394

395

flower-well developed. The expression of $V v E X O 70-11$ was the highest in the leaf-fruit set. $V v E X O 70-13$ had the highest expression in flesh-PHWIII. However, VvEXO70-04 did not expressed in pollen, bud, leaf, seedling and skin-ripening. VvEXO70-14 did not expressed in skin-rippen, flesh and pericarp. All $V v E X O 70-07, V v E X O 70-08, V v E X O 70-09$ and $V v E X O 70-10$ didn't expressed in leaf-sensecent, seedling, bud, carpel, pollen, seed, flesh-ripening, pericarp and skin-PHWI, -PHWII, -PHWIII.

\section{8. qRT-PCR analysis of VvEXO70s}

This study further verified and analyzed the relative expression characteristics of $V v E X O 70 \mathrm{~s}$. Figure. 7 showed that there were significant differences in the relative expression levels of part of genes when all $V v E X O 70 s$ genes were induced by different hormones and abiotic stresses about $12 \mathrm{~h}$ and $24 \mathrm{~h}$. The relative expression levels of all genes in $5 \mathrm{mM} \mathrm{SA}, 0.1 \mathrm{mM}$ MeJA, $20 \%$ PEG6000 and $4{ }^{\circ} \mathrm{C}$ for $24 \mathrm{~h}$ were all higher than that for $12 \mathrm{~h}$. Compared to the $\mathrm{CK}$, the relative expression quantity of $V v E X O 70-01,02,03,04,05,06,09,12,13$, and 14 up-regulated under $2 \mathrm{mM} \mathrm{ABA}$ treatment about $12 \mathrm{~h}$ and $24 \mathrm{~h}$. On the contrary VvEXO70-07's relative expression was significantly down-regulated. After 20\% PEG6000 treatment for $24 \mathrm{~h}$, the relative expression levels of $V v E X O 70-02$ and $V v E X O 70-05$ significantly up-regulate and were 361 and 219 times higher than that of CK respectively. When the leaves were subjected to $4^{\circ} \mathrm{C}$, VvEXO70-05 had the highest relative expression about $24 \mathrm{~h}$. With $2 \mathrm{mM}$ ABA about $12 \mathrm{~h}$, the relative expression of $V v E X O 70-05$ was highest. $V v E X O 70-13$ 's relative expression with $5 \mathrm{mM}$ SA about $24 \mathrm{~h}$ was the highest. Most of the genes were up-regulated after $0.1 \mathrm{mM} \mathrm{MeJA}$, especially $V v E X O 70-05$ 's at $24 \mathrm{~h}$. Under $7 \mathrm{mM} \mathrm{H}_{2} \mathrm{O}_{2}$, all genes' expression for $12 \mathrm{~h}$ were higher than $24 \mathrm{~h}$, among which $V v E X O 70-02,03,04,05,06$ and 14 significantly up-regulated. This result showed that many $V v E X O 70$ genes were likely to play critical roles in the abiotic and hormonal stress signaling transduction pathways.

\section{DISCUSSION}


396 Exocyst belongs to one of ancient families of the eukaryotic tetraploid system, which is an 397 octameric vesicle mesenteric complex acting upstream of SNARE mediated fusion of 398 extracellular vesicles with the plasma membrane (Whyte et al., 2002; Zhang et al., 2010). 399 EXO70, a subunit of the exocyst, together with SEC3 depends on PIP2 in the cell membrane 400 localization. Under the synergistic action of these three proteins, a cell membrane target polarity 401 site is established and then interacted with other 6 exocrine complex components to tether 402 exocrine vesicles to the cell membrane (He et al., 2007; Zhang et al., 2008; Li et al., 2010). This 403 study has found that $V v E X O 70$ gene family consisted of 7 subfamilies (Fig. 3 A), which could trace to three ancient $E X O 70$ genes existing in common ancestor of mosses and vascular plants, named EXO70.1, EXO70.2 and EXO70.3. These genes were independently replicated in mosses, lycopodium, and angiosperms lineages (Synek et al., 2006; Chong et al., 2010; Fatima et al., 407 2012).

408

409

410

411

412

413

414

415

416

417

418

419

420

421

422

In this experiment, a total of $14 V v E X O 70$ genes were obtained by bioinformatics and domain comparison, which were named $V v E X 070-01 \sim V v E X 070-14$. Grape, A. thaliana, rice protein sequence were used to construct an evolutionary tree divided into EXO70A J (Fig. 2), in which EXO70F, $\mathrm{H}$ and $\mathrm{J}$ did not contain $V v E X O 70$ gene, but only $O s E X O 70$ gene, which was the same as previous research groups (Fatima, et al., 2012; Yang et al., 2015 ). There were differences in the distribution of exons in the same subgroup, which was similar to the results of Yang et al., $\left(2015^{\mathrm{b}}\right)$ in cabbage and Chinese cabbage and this suggested that EXO70 genes may have some similarities in the evolution of different species. Multiple sequence alignment (Fig. 3 D) and motif analysis (Fig. 3 C) showed that VvEXO70 proteins contained a complete pfam03081 domain, which was composed of most of the $\alpha$-helix and was a key factor in determining the function of EXO70 proteins. Dellago et al., (2011) found that EXO70 could participate in premRNA clipping, and all known EXO70 interacted with other proteins. For this, the conservative pfam03081 may be a necessary domain for interaction with other proteins, but its specific function has not been further studied (Yang et al., 2015 a). Besides, the domain had two highly fractured bases, A and B (Fig. 3 D). The remaining genes contained all motifs except for 
$423 V v E X O 70-07$ and $V v E X O 70-12$, so we predicted that this gene family could have high structural

424 similarity and conservatism in the evolutionary process, and certain variation. It was found that 425 the C-terminal of EXO70 gene was the most conserved structural domain in the whole molecule, 426 which contained a large number of basic residues such as Arg and Lys. It was close to the plasma 427 membrane and further associated with Rho3p through the interaction between the clustered 428 alkaline residues and Rho3p (Dong et al., 2005; Hamburger et al., 2006).

429 Understanding the protein's subcellular location information (Table S4) may provide us with the 430 necessary help to infer the biological function of the protein, $V v E X O 70 s$ woud mainly locate in 431 nucleus, cytoplasm, chloroplast, mitochondria and plasma membrane so it was speculated to be 432 related to plant cytoplasmic secretion, photosynthesis, respiratory action and cell growth and 433 development. Plant tissue expression specificity (Fig. 6) found that most of $V v E X O 70$ gene were 434 expressed to varying degrees in pollen, tendrils, leaves, seeds, buds, roots and stems. Among 435 them, $V v E X O 70-01$ was mainly found in pollen and stamens. AtEXO70A1 expresses in all plant 436 tissues by gene chip and qRT-PCR (Synek et al., 2006; Chong et al., 2010). Moreover, Li et al., 437 (2010) also found that AtEXO70 gene mainly expresses in tissues with high exocrine activity, 438 such as elongated cells at growth points and developed xylem molecules, while the expression 439 was low in other tissues. Yang et al., (2000) detected BoEXO70A1 expression in stem, leaf, petal, 440 anther, stigma, style and ovary by the Northern method, indicating that it may be a constitutive 441 expression gene, but it still needs to be further detected. These indicated that the EXO70 genes 442 family may be related to the tip growth and elongation development of plants.

443 The collinear relationship (Fig. 5) between grape and A. thaliana EXO70 genes was analyzed, 444 and 23 pairs of collinear genes were found between grape and A. thaliana. Also, the $\mathrm{d}_{\mathrm{N}} / \mathrm{d}_{\mathrm{S}}$ values of these gene replication pairs were all less than 1, indicating that they had been purified and selected to predict their high conservatism in the evolution process (Table 2). The analysis of codon bias (Table S7) showed that the codon bias of the members of the gene family was weak and the degree of deviation from random selection was consistent. However, Yang et al., (2015 $)$ 
449 found that the codon bias of cabbage and chinese cabbage was almost identical, while that of $A$. 450 thaliana and rice was significantly different. Besides, according to the correlation of each 451 parameter, the base content in the third position of the synonymous codon has a high influence 452 on the gene expression level and codon preference, it was similar to Zhang et al., found in 2011. 453 This suggested that the resule of using codon preference in the evolutionary process to predict 454 the genomic location of EXO70 for unknown proteins in different species may be different.

455 When plants are under stress such as low temperature, drought and hormone, these stress signals 456 will be converted into signal factors, activate the cis-acting elements of transcription factor 457 binding genes and stimulate the expression of related genes and responding to stress (Shinozaki 458 et al., 1997; Teixeira et al., 2004; Hadiarto et al., 2011). The $2 \mathrm{~kb}$ upstream sequences of $459 V v E X O 70 s$ (Fig. 4) found that VvEXO70s contained various cis-acting elements such as G-box 460 and Box-4 elements related to light stress, and MYB and MYC elements related to drought 461 presented in all genes, suggesting that this gene family had certain drought resistance. qRT-PCR 462 (Fig. 7) suggested that $V v E X O 70$ s' relative expression were higher than CK with 20\% PEG6000 treatment for $24 \mathrm{~h}$, indicating that most of $V v E X O 70 \mathrm{~s}$ had drought resistance, which was similar to the results of cis-acting element. In addition, the $V v E X O 70 s$ also contained many other different cis-acting elements, such as 28, 30, and 40 components related to SA, MeJA, and ET, respectively. Pieterse et al., (2009) also find that plant hormones SA, MeJA and ET were important regulatory factors in plant resistance signal transduction pathways. It is speculated that these cis-acting elements could have a great role in plant growth and resistance. qRT-PCR (Fig. 7) found that many $V v E X O 70$ genes had different responses to stresses. For example, all genes'

470 relative expression in $5 \mathrm{mM} \mathrm{SA}, 0.1 \mathrm{mM} \mathrm{MeJA}, 20 \%$ PEG6000 and $4{ }^{\circ} \mathrm{C}$ for $24 \mathrm{~h}$ were all higher 471 than that for $12 \mathrm{~h}$. After 20\% PEG6000 treatment for $24 \mathrm{~h}$, the relative expression levels of $472 V v E X O 70-02$ and $V v E X O 70-05$ significantly up-regulate and were 361 and 219 times higher than 473 that of CK respectively. $V v E X O 70-13$ 's relative expression under $5 \mathrm{mM}$ SA for $24 \mathrm{~h}$ was the 474 highest. Most of genes up-regulatedly expressed with $0.1 \mathrm{mM} \mathrm{MeJA}$, especially $V v E X O 70-05$ 's 
475

476

477

478

479

480

481

482

483

484

485

486

487

488

489

490

491

492

493

494

495

496

497

498

499

500

501

at $24 \mathrm{~h}$. The relative expression level of all genes with $7 \mathrm{mM} \mathrm{H}_{2} \mathrm{O}_{2}$ for $12 \mathrm{~h}$ were higher than $24 \mathrm{~h}$, among which $V v E X O 70-02,03,04,05,06$ and 14 significantly up-regulated. VvEXO70-05 had the highest relative expression with $4{ }^{\circ} \mathrm{C}$ for $24 \mathrm{~h}$. With $2 \mathrm{mM} \mathrm{ABA}$ treatment for $12 \mathrm{~h}$, the relative expression of $V v E X O 70-05$ was the highest and of $V v E X O 70-07$ significantly downregulate compared to the $\mathrm{CK}$, This showed that many $V v E X O 70$ genes were likely to play critical roles in the abiotic and hormonal stress signaling transduction pathways.

\section{CONCLUSION}

$V v E X O 70$ gene family consists of 14 members, and most genes expressed to varying degrees in tendrils, leaves, seeds, buds, roots and stems. In addition, qRT-PCR analysis showed $V v E X O 70-$ 02, VvEXO70-03, VvEXO70-04, VvEXO70-05, VvEXO70-13 and $V v E X O 70-14$ may have certain function in resisting abiotic and hormone stresses. This provides ideas for further exploring the function of $V v E X O 70 s$ and breeding work of grape in the later stage.

\section{REFERENCE}

Bu C, Gao S, Dong SJ, Zhao L, Li SP. 2019. Advances in the study of exictus in response to plant and biological stress. Life Sciences 31:714-722

Cai HQ, Reinisch K, Ferro-Novick S 2007. Coats, tethers, Rabs, and SNAREs work together to mediate the intra cellular destination of a transport vesicle. Development Cell 12:671-682

Chen D, Latham J, Zhao H, Bisoffi M, Farelli J, Dunaway-Mariano D. 2012. Human brown fat inducible thioesterase variant 2 cellular localization and catalytic function. Biochemistry 51:6990-6999

Chong YT, Gidda SK, Sanford C, Parkinson J, Mullen RT, Goring DR. 2010. Characterization of the Arabidopsis thaliana exocyst complex gene families by phylogenetic, expression profiling, and subcellular localization studies. New Phytol 185:401-419

Dellago H, Löscher M, Ajuh P, Ryder U, Kaisermayer C, Grillari-Voglauer R, Fortschegger K, Gross S, Gstraunthaler A, Borth N, Eisenhaber F, Lamond AI, Grillari 
502

503

504

505

506

507

508

509

510

511

512

513

514

515

516

517

518

519

520

521

522

523

524

525

526

527

528

J. 2011. Exo70, a subunit of the exocyst complex, interacts with SNEV (hPrp19/ hPso4) and is involved in pre-mRNA splicing. Biochemical Journal 438:81-91

Dong G, Hutagalung AH, Fu CM, Novick P. 2005. The structures of exocyst subunit Exo70p and the Exo84p C-terminal domains reveal a comm on motif. Nature Structural \& Molecular Biology 12:1094-1100

Elias M, Drdova E, Ziak D, Bavlnka B, Hala M, Cvrckova F, Soukupova H, Zarsky V. 2003. The exocyst complex in plants. Cell Biology International 27:199-201

Fatima C, Michal G, Radek B, Michal H, Ivan K, Anamika R, Viktor Z. 2012. Evolution of the land plant exocyst complexes. Frontiers In Plant Science 3:159-172

Finger FP, Hughes TE, Novick P. 1998. Sec3p is a spatial landmark for polarized secretion in budding yeast. Cell 92:559-571

Goldman N, Yang Z. 1994. A codon-based model of nucleotide substitution for protein-coding DNA sequences. Molecular Biology and Evolution 11:725-736

Gu YN, Zavaliev R, Dong ZN. 2017. Membrane trafficking in plant immunity. Molecular Plant 10:1026-34

Guo W, Grant A, Novick P. 1999. Exo84p is an exocyst protein essential for secretion. The Journal of Biological Chemisitry 274:23558-23564

Gupta SK, Bhattacharyya TK, Ghosh TC. 2004. Synonymous codon usage in lactococcus lactis: mutational bias versus translational selection. Journal of Biomolecular Structure and Dynamics 21:1-9

Hadiarto T, Tran LS. 2011. Progress studies of drought-responsive genes in rice. Plant Cell Reports 30:297-310

Hamburger ZA, Hamburger AE, West AP, Weis WI. 2006. Crystal structure of the\& cerevisiae exocyst component Exo70p. Journal of Molecular Biology 356:9-21

Juraj S, Přemysl P, Jiří Š, Nemanja V, Viktor Ž, Martin P. 2017. Analysis of Exocyst Subunit EXO70 Family Reveals Distinct Membrane Polar Domains in Tobacco Pollen Tubes. Plant Physiology 173:1659-1675 
529

530

531

532

533

534

535

536

537

538

539

540

541

542

543

544

545

546

547

548

549

550

551

552

553

554

555

Jurgens G, Geldner N. 2002. Protein secretion in plants: from the trans-Golgi network to the outer space. Traffic 3:605-13

Li N, Li YY, Zheng CC, Huang JG, Zhang SZ. 2016. Genome-wide comparative analysis of the codon usage patterns in plants. Genes Genom 38:723-731

Li SP, Van OsGMA, Ren SC, Yu DL, Ketelaar T, Emons AMC, Liu CM. 2010. Expression and Functional Analyses of EXO70 Genes in Arabidopsis Implicate Their Roles in Regulating Cell Type-Specific Exocytosis. Plant Physiology 154:1819-1830

Lin T, Ni Z, Shen M, Chen L. 2002. High-frequency codon analysis and its application in codon analysis of tobacco. Journal of Xiamen University 41:551-554

Liu DM, Li X, Shen D, Novick P. 2018. Two subunits of the exocyst, Sec3p and Exo70p, can function exclusively on the plasma membrane. Molecular Biology of the Cell 29:736-750.

Ma WQ, Wang Y, Yao XM, Xu ZJ, An LG, Yin M. 2016. The role of Exo70 in vascular smooth muscle cell migration. Cellular \& Molecular Biology Letters, 20(1).

Marashi SA, Najafabadi HS. 2004. How reliable readjustment is: correspondence regarding A. fuglsang, "The 'effective number of codons'revisited". Biochem Biophysic Res Commun 324: $1-2$

Mathieson EM, Suda Y, Nickas M, Snydsman B, Davis TN, Muller EGD, Neiman AM. 2010. Vesicle docking to the spindle pole body is necessary to recruit the exocyst during membrane formation in Saccharomyces cerevisiae. Molecular Cell Biology 21:3693-3707

Moore BA, Robinson HH, Xu Z. 2007. The crystal structure of mouse Exo70 reveals unique features of the mammalian exocyst. Molecular Biology 371:410-21

Pieterse CM., Leon-Reyes A, Van der Ent S, Van Wees SC. 2009. Networking by smallmolecule hormones in plant immunity. Nature Chemical Biology 5:308-316

Ren J, Guo W. 2012. ERK1/2 regulate exocytosis through direct phosphorylation of the exocyst component Exo70. Development Cell 22:967-978

Samuel MA, Chong YT, Haasen KE, Aldea-Brydges MG, Stone SL, Goring DR. 2009. Cellular pathways regulating responses to compatible and selfincompatible pollen in Brassica 
556

557

558

559

560

561

562

563

564

565

566

567

568

569

570

571

572

573

574

575

576

577

578

579

580

581

and Arabidopsis stigmas intersect at Exo70A1, a putative component of the exocyst complex. Plant Cell 21:2655-71

Sharp PM, Li WH. 1986. An evolutionary perspective on synonymous codon usage in unicellular organisms. Journal of Molecular Evolution 24:28-38

Sharp PM., Li WH. 1987. The codon adaptation index-a measure of directional synonymous codon usage bias, and its potential applications. Nucleic Acids Research 15:1281-1295

Shinozaki K, Shinozaki KY. 1997. Gene expression and signal transduction in water- stress response. Plant Physiology 115:327-334

Sivaram MV, Saporita JA, Furgason ML, Boettcher AJ, Munson M. 2005. Dimerization of the exocyst protein Sec6p and its interaction with the t-SNARE Sec9p. Biochemistry 44:6302 $-6311$

Synek L, Schlager N, Elias M, Quentin M, Hauser MT, Zarsky V. 2006. AtEXO70A1, a member of a family of putative exocyst subunits specifically expanded in land plants, is important for polar growth and plant development. The Plant Journal 48:54-72

Satapathy SS, Sahoo AK, Ray SK, Ghosh TC. 2017. Codon degeneracy and amino acid abundance influence the measure of codon usage bias: improved $\mathrm{Nc}(\mathrm{N} \quad \mathrm{c})$ and ENCprime ( N ' c ) measures. Genes to Cell 22 277-283

Teixeira FK, Menezes-benavente L, Margis R, Margis-pinheiro M. 2004. Analysis of the molecular evolutionary history of the ascorbate peroxidase gene family: inferences from the rice genome. Journal of Molecular Evolution 59:761 - 770

TerBush DR, Novick P. 1995. Sec6, Sec8, and Sec15 are components of a multisubunit complex which localizes to small bud tips in Saccharomyces cerevisiae. Jorunal of Cell Biology 130:299-312

TerBush DR., Maurice T, Roth D, Novick P. 1996. The exocyst is a multiprotein complex required for exocytosis in Saccharomyces cerevisiae. European Molecular Biology Organization 15:6483-6494 
582

583

584

585

586

587

588

589

590

591

592

593

594

595

596

597

598

599

600

601

602

603

604

605

606

607

608

Udvardi MK, Czechowski T, Scheible WR. 2008. Eleven golden rules of quantitative RT-PCR. Plant Cell 20:1736-1737

Wang Z, Li P, Yang Y, Chi Y, Fan B, Chen Z. 2016. Expression and functional analysis of a novel group of legume-specific wrky and exo70 protein variants from soybean. Entific Reports 6(1), 32090

Whyte JRC, Munro S. 2002. Vesicle tethering complexes in membrane traffic. Journal of Cell Science 115:2627-37

Wright F. 1990. The effective number of codons used in a gene. Gene 87:23-29

Wu H, Turner C, Gardner J, Temple B, Brennwald P. 2010. The Exo70 subunit of the exocyst is an effector for both Cdc42 and Rho3 function in polarized exocytosis. Molecular Cell Biology 21:430-442

WU XM, WU SF, REN DM, Zhu YP, He FC. 2007. The analysis method and progress in the study of codon bias. Hereditas 29:420-426

Yadav CB, Bonthala VS, Muthamilarasan M, Pandey G, Khan Y, Prasad M. 2015. Genome-wide development of transposable elements-based markers in foxtail millet and construction of , an integrated database. DNA Research 22:79-90

Yang Z, Bielawski JP. 2000. Statistical methods for detecting molecular adaptation. Trends in Ecology\&amp;Evolution 15:496-503

Yang K, Zhang Y, Lu J, Zhao YB, Zhang HC, Han X, He GH. 2015a. Comparison of EXO70 duplication between Arabidopsis thaliana and Oryza sativa. Science Bulletin 60:3858

Yang K, Lu J, Zhang Y, Zhao YB, Zhang HC, Han X, Xu JH, Lu HX, Shi SM. $2015 b$. EXO70 gene duplication and divergent evolution in Brassica oleracea and B.rapa. Science Bulletin 60:2304-2347

Yang JJ, Yu DL, Chu W, Li H, Li SP. 2013. Research Advance of the EXO70 Gene Family in Plants. Chinese Journal of Plant Physiology 49:882-888

Yao XM, Wu QH, An LG, Yin M. 2013. Advance in subunit of exocyst complex --- Exo70. 
609

610

611

612

613

614

615

616

617

618

619

620

621

622

623

624

625

626

627

628

629

630

631

632

633

634

635

636

Chemistry of Life 33:29-33

Yu D, Overdijk EJR, Berg J A, Francine G, Klaas B. 2018. Solanaceous exocyst subunits are involved in immunity to diverse plant pathogens. Journal of Experimental Botany 3:655666

Yun HS, Kwon C. 2017. Vesicle trafficking in plant immunity. Current Opinion in Plant Biology 40:34-42

Zhang L, Jin LG, Luo L, Wang YP, Dong ZM, Sun SH, Qiu LJ. 2011. Analysis of Nuclear Gene Codon Bias on Soybean Genome and Transcriptome. Acta Agronomica Sinica 37:965 $-974$

Zhang X, Orlando K, He B, Xi FG, Zhang J, Zajac A, Guo W. 2008. Membrane association and functional regulation of Sec3 by phospholipids and Cdc42. Jorunal of Cell Biology, 180: $145-158$

Zhang Y, Liu CM, Emons AMC, Ketelaar T. 2010. The plant exocyst. Journal of Integrative Plant Biology 52:138-146

Zhao J, Zhang X, Wan WT, Zhang H, Liu J, Li ML, Wang HY, Xiao J, Wang X. 2018. Identification and Characterization of the EXO70 Gene Family in Polyploid Wheat and Related Species. International Journal of Molecular Sciences 20:60

Zhu YY, Wu B, Guo W. 2019. The role of Exo70 in exocytosis and beyond. Small GTPases 10:331-335

Figure Legends

Table 1. Physicochemical property analysis of $V v E X O 70$ gene family.

Table 2. Selective pressure analysis of $V v E X O 70$ gene family.

Fig. 1. Distribution of $V v E X O 70$ gene family on chromosome. Chromosomal locations of 14 
$637 V v E X O 70$ genes. The red stripe represents some of the chromosomes in the grape, and the 638 chromosome number is showed at the top of each red stripe.

639

640 Fig. 2. Grape, A. thaliana, rice evolution tree of EXO70 gene family. White circle, triangle, star 641 represent grapes, $A$. thaliana, and rice EXO70 genes, respectively. Lines and background with 642 different colors represent different subgroups.

643

644 Fig. 3. Gene structure, motif and multiple sequence analysis of $V v E X O 70$ gene family. A) 645 Cluster analysis of $V v E X O 70 s$. B) Genes structure of $V v E X O 70 s$. The exon, intron and 646 upstream/downstream are represented by red boxes, gray lines and black boxes. C) Protein motif. 647 Different color represented different motif. D) Multiple sequence result.

648

649

Fig. 4. cis-acting elements existed in the $2 \mathrm{~kb}$ upstream region of $V v E X O 70$ gene family. The 650 distribution of the $24 \mathrm{cis}$-acting elements in the promoter sequence of $14 V v E X O 70$ genes, shown 651 in different colors. ABRE, cis-acting element involved in the abscisic acid responsiveness. ARE 652 (anaerobic induction). AuxRR-core (auxin responsiveness). Box-4 (part of a conserved DNA 653 module involved in light responsiveness). CAT-box (meristem expression). CGTCA-motif 654 (MeJA-responsiveness). DRE (Drought). ERE (ETH). G-Box (light responsiveness). GARE655 Motif (gibberellin-responsive). LTR (low-temperature responsiveness). MBS (MYB binding site 656 involved in drought-inducibility). MYB (Drought). O2-site (zein metabolism regulation). P-box 657 (gibberellin-responsive). STRE (Pressure). as-1 (SA). TCA-element (SA). TGA-element (auxinresponsiv). TGACG-Motif (MeJA-responsiveness). WUN-motif (callus). Circadian (circadian 659 control).

660

661 Fig. 5. Collinearity analysis of the EXO70 gene family between grape and $A$. thaliana. The color 662 of the strips represents the extent of similarity and homology among the genes. Blue indicates the 663 lowest similarity, followed by orange, green and red, indicating the increasing similarity. 
665 Fig. 6. The expression pattern of $V v E X O 70$ gene family in different tissues and organs. The band 666 indicates the level of gene expression on right.

667

Fig. 7. Analysis of qRT-PCR expression results of $V v E X O 70$ gene family. $14 V v E X O 70$ genes 669 were analyzed by qRT-PCR which were used to assess $V v E X O 70$ relative expression levels in 670 leaves sampled at $12 \mathrm{~h}$ and $24 \mathrm{~h} . \mathrm{A} \sim \mathrm{N}$ represent $V v E X 070-01 \sim V v E X O 70-14$ gene, 671 respectively. Yellow and blue represent the relative expression for $12 \mathrm{~h}$ and $24 \mathrm{~h}$, respectively. 


\section{Figure 1}

Fig. 1 Distribution of VvEXO70 gene family on chromosome

Distribution of VvEXO70 gene family on chromosome. Chromosomal locations of 14 VvEXO70 genes. The red stripe represents some of the chromosomes in the grape, and the chromosome number is showed at the top of each red stripe.

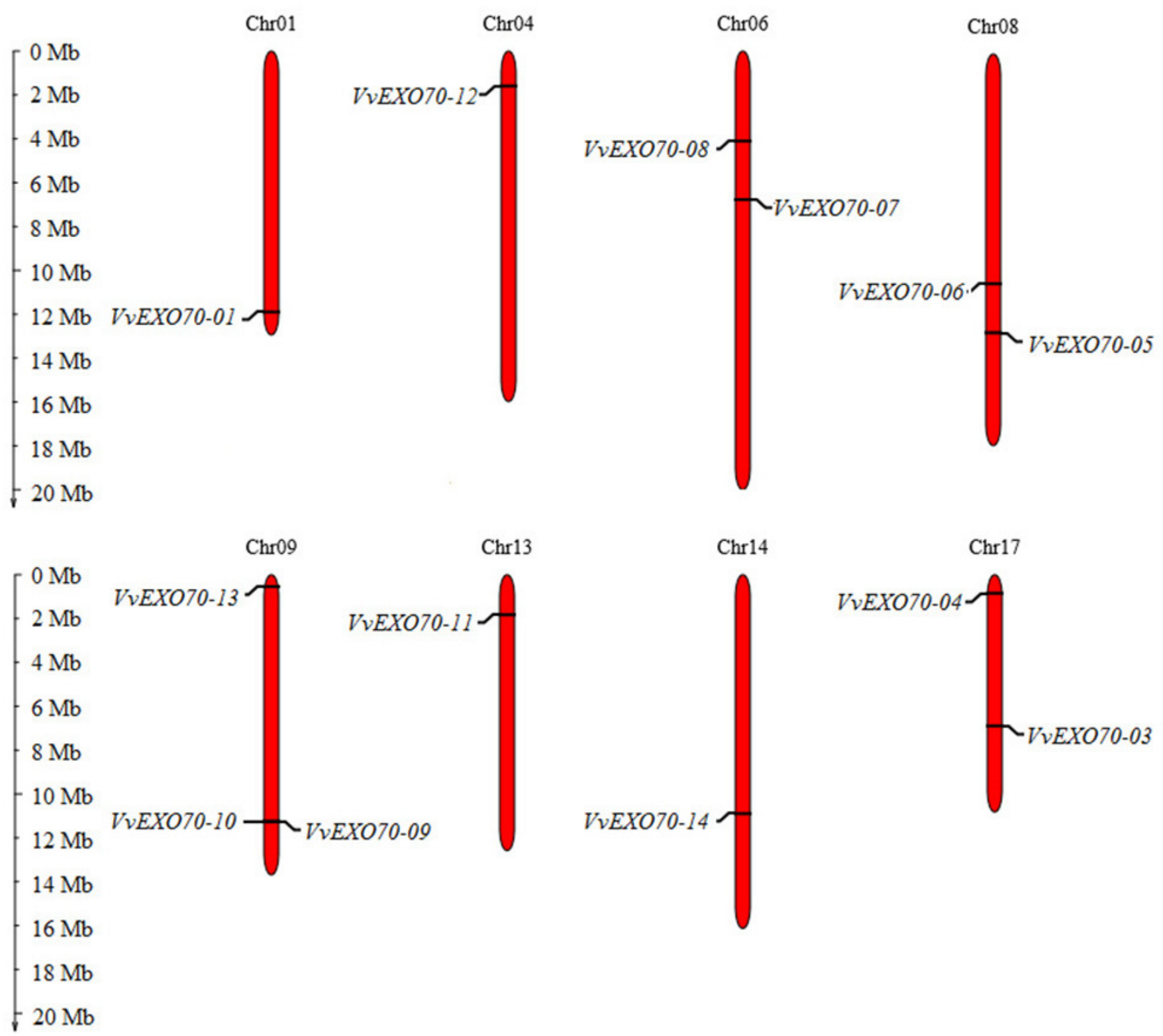




\section{Figure 2}

Fig. 2 Grape, Arabidopsis thaliana, rice evolution tree of EXO70 gene family

Grape, $A$. thaliana, rice evolution tree of EXO70 gene family. White circle, triangle, star represent grapes, $A$. thaliana, and rice EXO70 genes, respectively. Lines and background with different colors represent different subgroups.

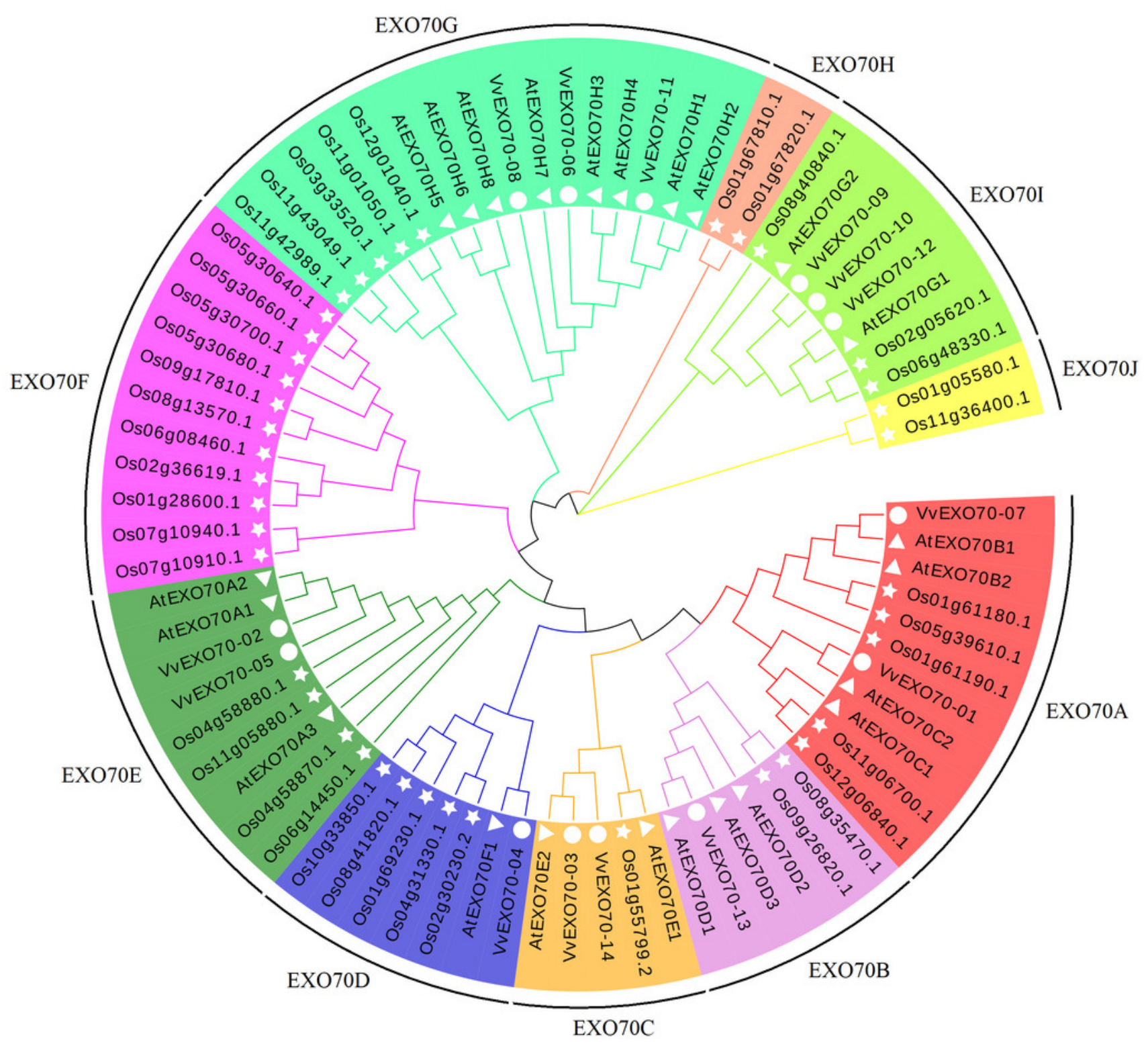




\section{Figure 3}

Fig. 3 Gene structure, motif and multiple sequence analysis of VVEXO70 gene family

Gene structure, motif and multiple sequence analysis of VvEXO70 gene family. A) Cluster analysis of VvEXO70s. B) Genes structure of VvEXO70s. The exon, intron and upstream/downstream are represented by red boxes, gray lines and black boxes. C) Protein motif. Different color represented different motif. D) Multiple sequence result. 


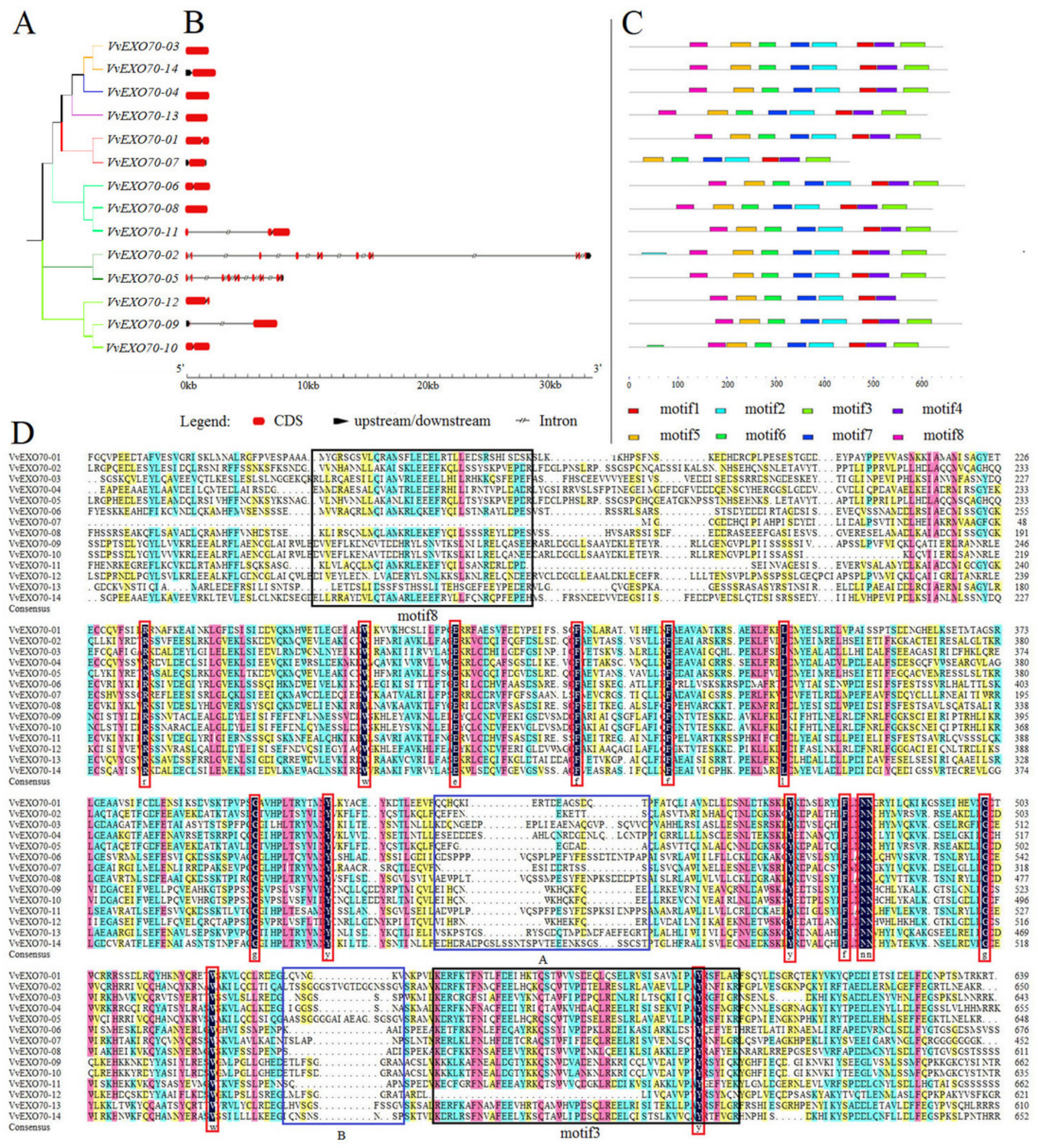




\section{Figure 4}

Fig. 4 cis-acting elements existed in the $2 \mathrm{~kb}$ upstream region of VvEXO70 gene family

cis-acting elements existed in the $2 \mathrm{~kb}$ upstream region of $V V E X O 70$ gene family. The distribution of the 24 cis-acting elements in the promoter sequence of 14 VVEXO70 genes, shown in different colors. ABRE, cis-acting element involved in the abscisic acid responsiveness. ARE (anaerobic induction). AuxRR-core (auxin responsiveness). Box-4 (part of a conserved DNA module involved in light responsiveness). CAT-box (meristem expression). CGTCA-motif (MeJA-responsiveness). DRE (Drought). ERE (ETH). G-Box (light responsiveness). GARE-Motif (gibberellin-responsive). LTR (low-temperature responsiveness). MBS (MYB binding site involved in drought-inducibility). MYB (Drought). 02-site (zein metabolism regulation). P-box (gibberellin-responsive). STRE (Pressure). as-1 (SA). TCAelement (SA). TGA-element (auxin-responsiv). TGACG-Motif (MeJA-responsiveness). WUNmotif (callus). Circadian (circadian control).

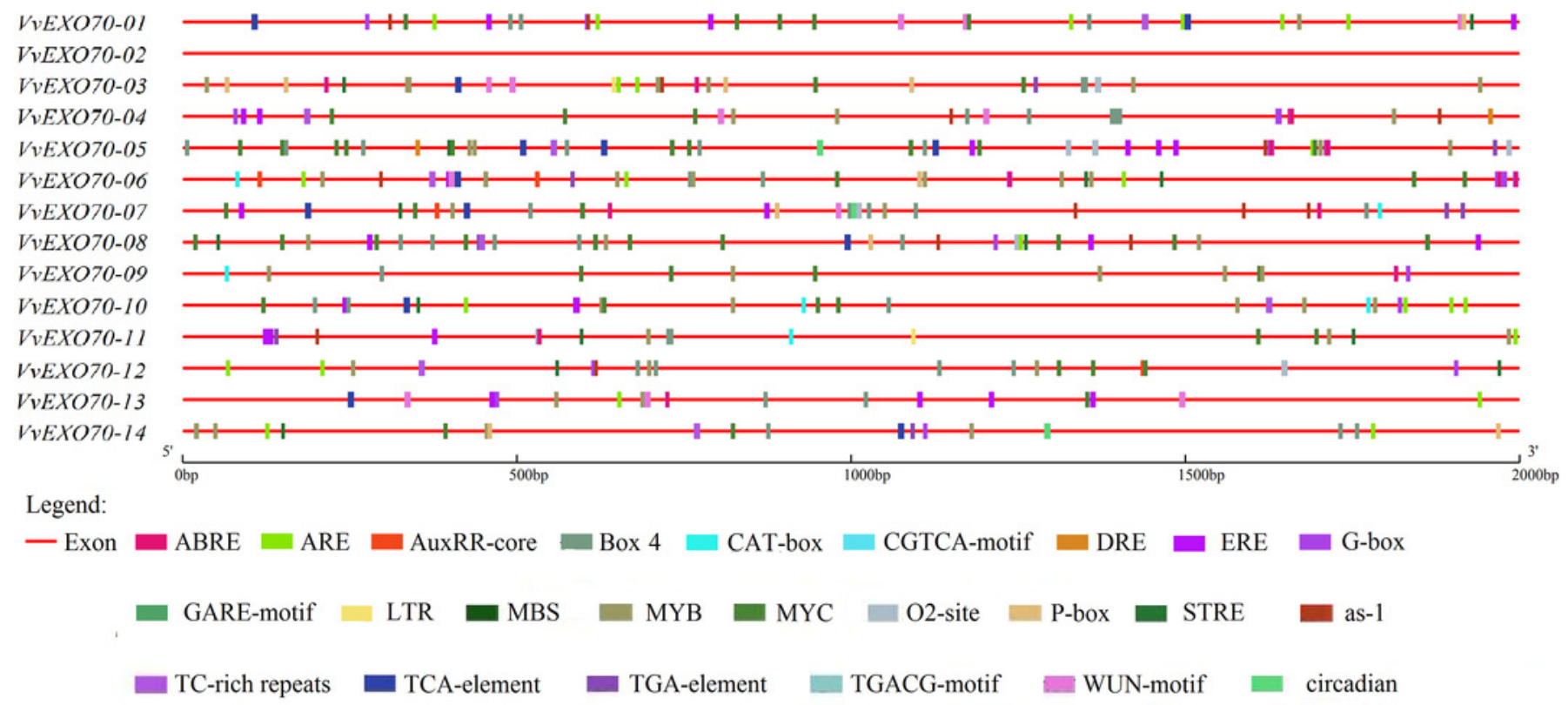




\section{Figure 5}

Fig. 5 Collinearity analysis of the EXO70 gene family between grape and Arabidopsis thaliana

Collinearity analysis of the EXO70 gene family between grape and $A$. thaliana. The color of the strips represents the extent of similarity and homology among the genes. Blue indicates the lowest similarity, followed by orange, green and red, indicating the increasing similarity. 


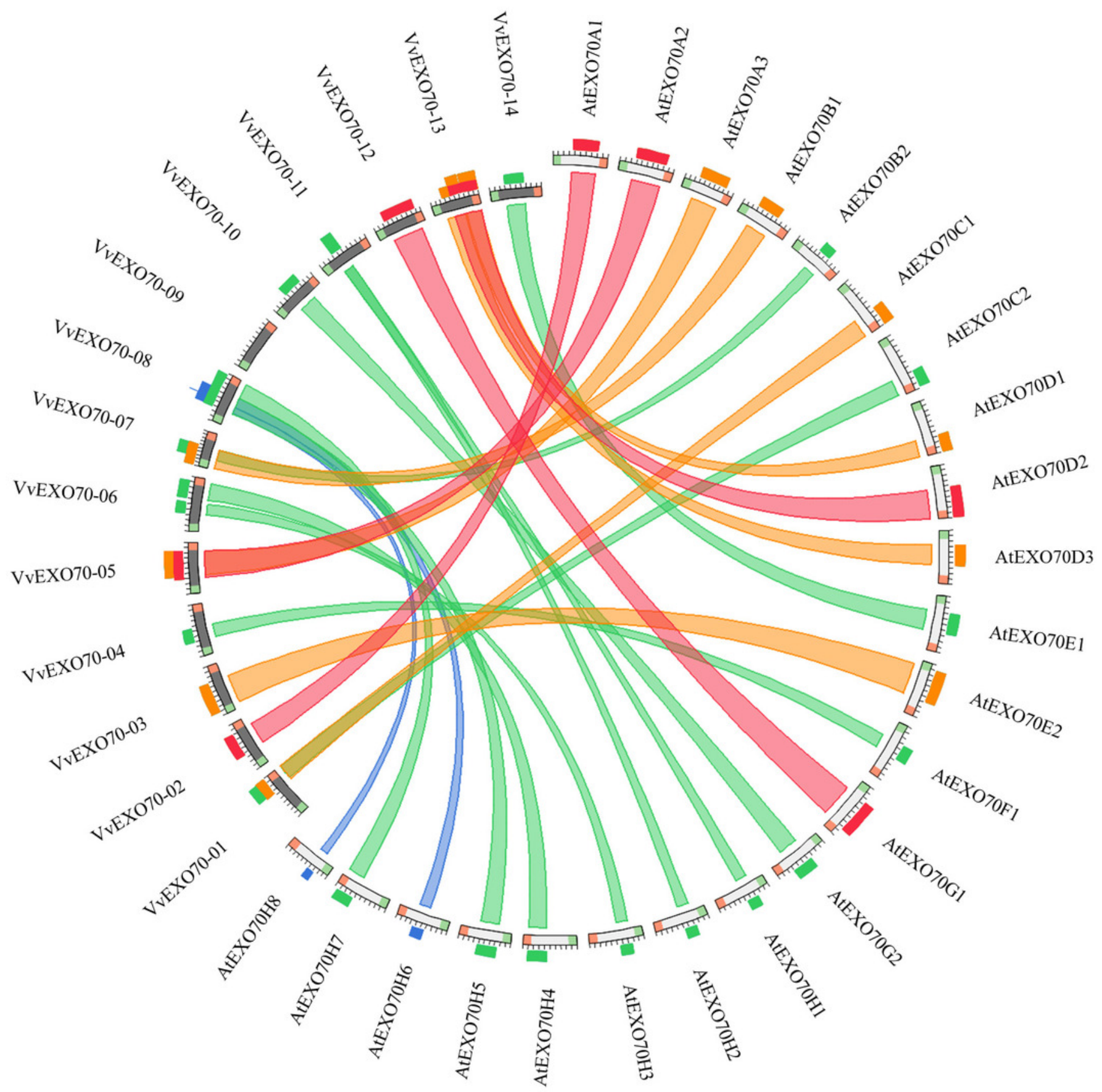


Figure 6

Fig. 6 The expression pattern of VvEXO70 gene family in different tissues and organs

The expression pattern of $V V E X O 70$ gene family in different tissues and organs. The band indicates the level of gene expression on right.

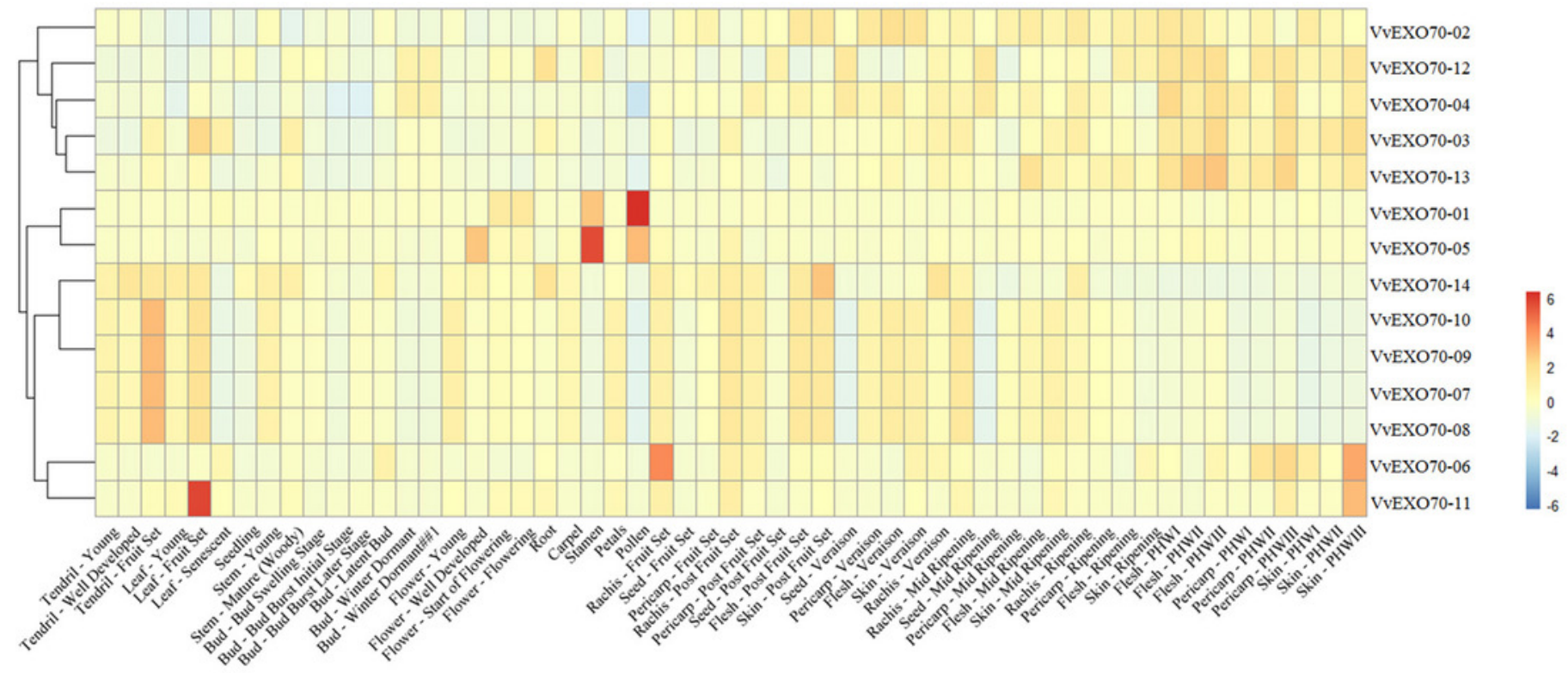


Figure 7

Fig. 7 Analysis of qRT-PCR expression results of VvEXO70 gene family

Analysis of qRT-PCR expression results of VvEXO70 gene family. 14 VvEXO70 genes were analyzed by qRT-PCR which were used to assess VvEXO70 relative expression levels in leaves sampled at $12 \mathrm{~h}$ and $24 \mathrm{~h} . \mathrm{A} \sim \mathrm{N}$ represent $V v E X 070-01 \sim V_{v}$ EXO70-14 gene, respectively. Yellow and blue represent the relative expression for $12 \mathrm{~h}$ and $24 \mathrm{~h}$, respectively.
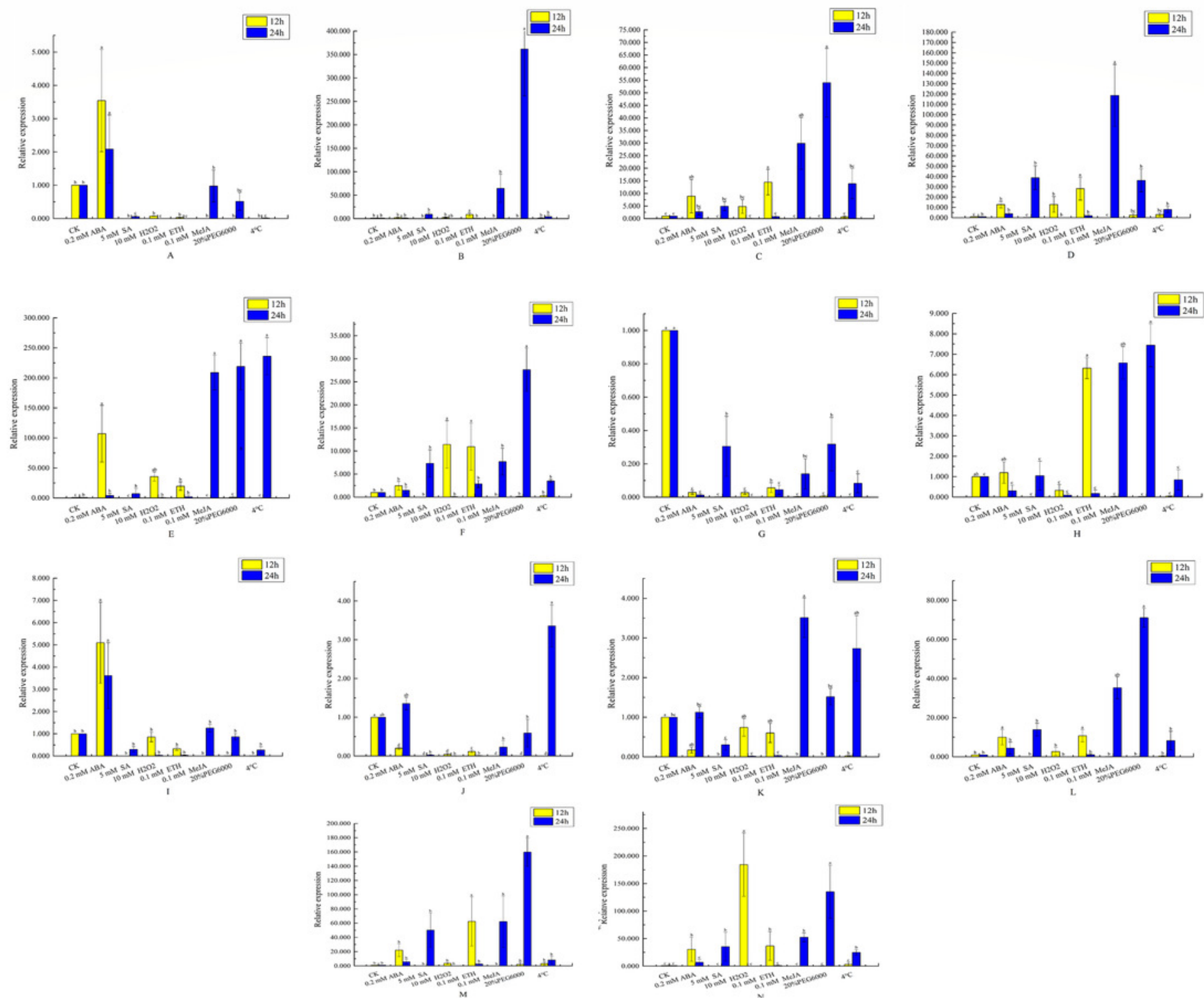


\section{Table $\mathbf{1}$ (on next page)}

Table1 Physicochemical property analysis of VvEXO70 gene family 
1

2

Table1 Physicochemical property analysis of VvEXO70 gene family

\begin{tabular}{|c|c|c|c|c|c|c|c|c|c|c|}
\hline Gene & Gene accession No. & $\begin{array}{l}\text { Length } \\
\text { of CDS }\end{array}$ & Length & $\begin{array}{l}\text { Length of } \\
\text { amino acid }\end{array}$ & Exon & $\begin{array}{c}\text { Molecular } \\
\text { weight }\end{array}$ & $\begin{array}{c}\text { Isoelectric } \\
\text { Point }\end{array}$ & $\begin{array}{l}\text { Instability } \\
\text { index }\end{array}$ & $\begin{array}{l}\text { Aliphatic } \\
\text { index }\end{array}$ & $\begin{array}{c}\text { Grand average of } \\
\text { hydropathicity }\end{array}$ \\
\hline VvEXO70-01 & GSVIVP00006977001 & 1920 & 1965 & 639 & 2 & 72341.22 & 5.18 & 53.78 & 72.18 & -0.554 \\
\hline$V v E X O 70-02$ & GSVIVP00013809001 & 1953 & 33699 & 650 & 12 & 73686.77 & 8.12 & 45.36 & 84.03 & -0.443 \\
\hline$V v E X O 70-03$ & GSVIVP00016199001 & 1932 & 1932 & 643 & 1 & 73525.06 & 5.56 & 46.58 & 96.30 & -0.304 \\
\hline VvEXO70-04 & GSVIVP00017936001 & 1974 & 1974 & 657 & 1 & 74221.00 & 4.89 & 47.88 & 87.88 & -0.358 \\
\hline$V v E X O 70-05$ & GSVIVP00021515001 & 1947 & 8150 & 648 & 11 & 73278.55 & 7.34 & 44.58 & 86.59 & -0.406 \\
\hline$V v E X 070-06$ & GSVIVP00023109001 & 2067 & 2085 & 688 & 2 & 77426.01 & 6.78 & 57.26 & 78.43 & -0.344 \\
\hline VvEXO70-07 & GSVIVT00024003001 & 1363 & 1733 & 452 & 1 & 51585.27 & 6.74 & 49.77 & 94.49 & -0.224 \\
\hline$V v E X O 70-08$ & GSVIVP00024408001 & 2067 & 2085 & 621 & 1 & 70148.30 & 6.21 & 53.02 & 78.68 & -0.362 \\
\hline VvEXO70-09 & GSVIVP00025283001 & 2052 & 7574 & 683 & 2 & 77236.89 & 7.84 & 41.42 & 98.78 & -0.178 \\
\hline VvEXO70-10 & GSVIVP00025287001 & 1971 & 2007 & 656 & 2 & 74589.93 & 6.60 & 40.11 & 100.93 & -0.170 \\
\hline$V v E X O 70-11$ & GSVIVP00029521001 & 2025 & 8680 & 674 & 3 & 76259.83 & 6.62 & 44.74 & 94.33 & -0.023 \\
\hline$V v E X O 70-12$ & GSVIVP00032320001 & 1899 & 2004 & 632 & 2 & 71019.17 & 6.85 & 42.21 & 106.65 & -0.108 \\
\hline$V v E X O 70-13$ & GSVIVP00034051001 & 1836 & 1836 & 611 & 1 & 69560.89 & 5.34 & 50.30 & 92.13 & -0.301 \\
\hline$V v E X O 70-14$ & GSVIVP00038035001 & 1959 & 2491 & 652 & 1 & 73953.32 & 4.82 & 51.84 & 90.90 & -0.370 \\
\hline
\end{tabular}

3

4

5 
Table 2 (on next page)

Table2 Selective pressure analysis of VvEXO70 gene family 


\begin{tabular}{|c|c|c|c|c|c|c|}
\hline Ribbon color & A pair of genes & $\mathrm{S}$ & $\mathrm{N}$ & $\mathrm{d}_{\mathrm{S}}$ & $d_{N}$ & $\mathrm{~d}_{\mathrm{N}} / \mathrm{d}_{\mathrm{S}}$ \\
\hline \multirow{9}{*}{ Red } & $V v E X O 70-02 \sim$ & 466.2 & 1447.8 & 1.4522 & 0.0966 & 0.0665 \\
\hline & AtEXO70A1 & & & & & \\
\hline & $V v E X O 70-05 \sim$ & 463.9 & 1429.1 & 1.6586 & 0.1357 & 0.0818 \\
\hline & AtEXO70A2 & & & & & \\
\hline & & & & & & \\
\hline & $V v E X O 70-12 \sim$ & 444.8 & 1451.2 & 2.1721 & 0.1488 & 0.0685 \\
\hline & AtEXO70G1 & & & & & \\
\hline & $V v E X O 70-13 \sim$ & 449.1 & 1362.9 & 4.5850 & 0.2343 & 0.0511 \\
\hline & AtEXO70D2 & & & & & \\
\hline \multirow{13}{*}{ Orange } & $V v E X 070-01 \sim$ & 446.5 & 1407.5 & 49.3070 & 0.3641 & 0.0074 \\
\hline & AtEXO70C1 & & & & & \\
\hline & $V v E X O 70-03 \sim$ & 495.2 & 1406.8 & 2.8294 & 0.4196 & 0.1483 \\
\hline & AtEXO70E2 & & & & & \\
\hline & $V v E X O 70-05 \sim$ & 146.4 & 1323.6 & 2.1672 & 0.3704 & 0.1709 \\
\hline & AtEXO70A3 & & & & & \\
\hline & & & & & & \\
\hline & $V v E X O 70-07 \sim$ & 348.6 & 1001.4 & 2.5887 & 0.1652 & 0.0638 \\
\hline & AtEXO70B1 & & & & & \\
\hline & $V v E X O 70-13 \sim$ & 452.6 & 1362.4 & 3.6151 & 0.2335 & 0.0646 \\
\hline & AtEXO70D1 & & & & & \\
\hline & $V v E X O 70-13 \sim$ & 450.1 & 1355.9 & 2.8325 & 0.2158 & 0.0762 \\
\hline & AtEXO70D3 & & & & & \\
\hline \multirow{5}{*}{ Green } & $V v E X 070-01 \sim$ & 421.2 & 1483.8 & 6.1042 & 0.3901 & 0.0639 \\
\hline & AtEXO70C2 & & & & & \\
\hline & & & & & & \\
\hline & $V v E X O 70-04 \sim$ & 415.3 & 1516.7 & 5.6402 & 0.2153 & 0.0382 \\
\hline & AtEXO70F 1 & & & & & \\
\hline
\end{tabular}




\begin{tabular}{|c|c|c|c|c|c|c|}
\hline & $\begin{array}{c}V v E X O 70-06 \sim \\
\text { AtEXO70H3 }\end{array}$ & 470.6 & 1380.4 & 3.1632 & 0.4221 & 0.1334 \\
\hline & $\begin{array}{c}V v E X O 70-06 \sim \\
\text { AtEXO70H4 }\end{array}$ & 480.9 & 1382.1 & 39.8698 & 0.3318 & 0.0083 \\
\hline & $\begin{array}{c}V v E X O 70-07 \sim \\
\text { AtEXO70B2 }\end{array}$ & 369.1 & 950.9 & 3.8067 & 033113 & 0.0818 \\
\hline & $\begin{array}{l}V v E X O 70-08 \sim \\
\text { AtEXO70H5 }\end{array}$ & 446.4 & 1323.6 & 13.2657 & 0.4503 & 0.0339 \\
\hline & $\begin{array}{l}V v E X O 70-08 \sim \\
\text { AtEXO70H7 }\end{array}$ & 463.4 & 1354.6 & 5.5653 & 0.3917 & 0.0704 \\
\hline & $\begin{array}{c}V v E X O 70-10 \sim \\
\text { AtEXO70G2 }\end{array}$ & 489.8 & 1448.2 & 4.1836 & 0.5181 & 0.1238 \\
\hline & $\begin{array}{c}V v E X O 70-11 \sim \\
\text { AtEXO70H1 }\end{array}$ & 450.4 & 1343.6 & 4.0569 & 0.3224 & 0.0795 \\
\hline & $\begin{array}{c}V v E X O 70-11 \sim \\
\text { AtEXO70H2 }\end{array}$ & 468.3 & 1331.7 & 2.6233 & 0.3326 & 0.1268 \\
\hline & $\begin{array}{c}V v E X O 70-14 \sim \\
\text { AtEXO70E1 }\end{array}$ & 481.7 & 1438.3 & 7.4183 & 0.3943 & 0.0531 \\
\hline & $\begin{array}{l}V v E X O 70-08 \sim \\
\text { AtEXO70H6 }\end{array}$ & 440.3 & 1335.7 & 17.8262 & 0.4608 & 0.0258 \\
\hline Blue & $\begin{array}{c}V v E X O 70-08 \sim \\
\text { AtEXO70H8 }\end{array}$ & 444.5 & 1256.5 & 34.1171 & 0.4399 & 0.0129 \\
\hline
\end{tabular}

2 